OPEN ACCESS

Edited by:

Hugo Caire Castro-Faria-Neto, Oswaldo Cruz Foundation (Fiocruz),

Brazil

Reviewed by:

Eduardo Tibirica,

Instituto Nacional de Cardiologia,

Brazil

Maria G. Petrillo,

National Institute of Environmental Health Sciences (NIEHS), United States

*Correspondence: Antonio Barbieri

a.barbieri@istitutotumori.na.it

${ }^{\dagger}$ These authors share last authorship

Specialty section: This article was submitted to Inflammation,

a section of the journal

Frontiers in Immunology

Received: 29 July 2020 Accepted: 17 September 2020 Published: 30 September 2020

Citation:

Barbieri A, Robinson N, Palma G, Maurea N, Desiderio V and Botti G

(2020) Can Beta-2-Adrenergic Pathway Be a New Target to Combat SARS-CoV-2 Hyperinflammatory Syndrome?-Lessons Learned From Cancer.

Front. Immunol. 11:588724. doi: 10.3389/fimmu.2020.588724

\section{Can Beta-2-Adrenergic Pathway Be a New Target to Combat SARS-CoV-2 Hyperinflammatory Syndrome? - Lessons Learned From Cancer}

\author{
Antonio Barbieri ${ }^{1 *}$, Nirmal Robinson ${ }^{2}$, Giuseppe Palma ${ }^{1}$, Nicola Maurea ${ }^{3}$, \\ Vincenzo Desiderio ${ }^{4 t}$ and Gerardo Botti ${ }^{5 t}$

\begin{abstract}
'Animal Facility, Istituto Nazionale Tumori, Istituto Di Ricovero e Cura a Carattere Scientifico "Fondazione G. Pascale", Naples, Italy, ${ }^{2}$ Centre for Cancer Biology, University of South Australia and SA Pathology, Adelaide, SA, Australia, ${ }^{3}$ Division of Cardiology, Istituto Nazionale Tumori, Istituto Di Ricovero e Cura a Carattere Scientifico (IRCCS) "Fondazione G. Pascale", Naples, Italy, ${ }^{4}$ Section of Histology, Department of Experimental Medicine, University of Campania "Luigi Vanvitelli", Naples, Italy, ${ }^{5}$ Scientific Directorate, Istituto Nazionale Tumori, IRCCS "Fondazione G. Pascale", Naples, Italy
\end{abstract}

SARS-CoV-2 infection is a new threat to global public health in the $21^{\text {st }}$ century (2020), which has now rapidly spread around the globe causing severe pneumonia often linked to Acute Respiratory Distress Syndrome (ARDS) and hyperinflammatory syndrome. SARSCoV-2 is highly contagious through saliva droplets. The structural analysis suggests that the virus enters human cells through the ligation of the spike protein to angiotensinconverting enzyme $2\left(\mathrm{ACE}_{2}\right)$. The progression of Covid-19 has been divided into three main stages: stage I-viral response, stage II-pulmonary phase, and stage IIIhyperinflammation phase. Once the patients enter stage III, it will likely need ventilation and it becomes difficult to manage. Thus, it will be of paramount importance to find therapies to prevent or slow down the progression of the disease toward stage III. The key event leading to hyperinflammation seems to be the activation of Th-17 immunity response and Cytokine storm. $B_{2}$-adrenergic receptors $\left(B_{2} A R s\right)$ are expressed on airways and on all the immune cells such as macrophages, dendritic cells, B and $T$ lymphocytes. Blocking $\left(B_{2} A R\right)$ has been proven, also in clinical settings, to reduce Th-17 response and negatively modulate inflammatory cytokines including IL-6 while increasing IFN $\gamma$. Non-selective beta-blockers are currently used to treat several diseases and have been proven to reduce stress-induced inflammation and reduce anxiety. For these reasons, we speculate that targeting $B_{2} A R$ in the early phase of Covid-19 might be beneficial to prevent hyperinflammation.

Keywords: COVID-19, SARS-CoV2, Beta adrenergic receptors, beta-blockers, Cytokine storm, immune response, hyperinflammation 


\section{BACKGROUND}

Coronaviruses are a variable group of enveloped, positive-sense, single-stranded RNA viruses (1). They cause several diseases involving respiratory, enteric, hepatic, and neurological systems with high severity among humans and animals $(1,2)$. In the last two decades, the entire world witnessed two novel types of coronavirus, severe acute respiratory syndrome CoV (SARS$\mathrm{CoV}$ ) and Middle East respiratory syndrome CoV (MERS$\mathrm{CoV})$, causing severe human diseases $(3,4)$. In December 2019 an outbreak of pneumonia of unknown cause occurred in Wuhan, Hubei Province, China that rapidly spread around the globe, reaching to pandemic dimensions, and it was later named as SARS-CoV-2 or COVID-19 $(5,6)$. The main symptoms of COVID-19 include fever, fatigue, and cough, which are similar to that of SARS-CoV and MERS-CoV infected cases. SARS-CoV-2 is closely related to other coronaviruses ( $88 \%$ identity) which likely originated from bats. SARS-CoV-2 enters the human cells through $\mathrm{ACE}_{2}$ receptors after ligation of spike protein. These receptors are highly expressed in the lung but are also found in other organs such as the heart, kidney, endothelium, and intestine (7-9). Notably, $\mathrm{ACE}_{2}$ is highly expressed on the luminal surface of intestinal epithelial cells, functioning as a co-receptor for nutrient uptake, in particular for amino acid resorption from food (10). For this reason, the intestine might also be a putative entry site for SARS-CoV-2 and that the infection might have been initiated by eating food from wild animals. To date the virus has infected hundreds of thousands of people, and about half of the hospitalized patients show clinical signs of comorbidities such as hypertension (23.7-30\%), diabetes mellitus (16.2\%), coronary heart diseases (5.8\%), and cerebrovascular disease $(2.3 \%)$. Also, a high rate of mortality has been reached when one or more comorbidities coexist. Covid-19 infection associated symptoms, including acute respiratory distress syndrome (ARDS) and septic shock seem to be associated with hyperinflammation and cytokine storm as in patients' serum the levels of several cytokines are elevated (11). In particular IL-6, IL-1 $\beta$, IL-10, TNF, GM-CSF, IP-10 (IFNinduced protein 10), IL-17,MCP-3, and IL-1ra are mainly involved both in mild and severe forms of disease and altered circulating leukocyte subset and cytokine secretion (12). As many of these cytokines are involved in the Th17 type response, $\mathrm{Wu}$ and Yang suggested that targeting the Th17 pathway may counteract the Covid-19 symptoms (13). This hypothesis relies on different pieces of evidence: IL-6, TNF $\alpha$, and IL- $1 \beta$ promote Th17 response and are associated with inflammatory symptoms including fever, and the two latter are also associated with vascular permeability and leakage; IL-17 has a broad inflammatory effect and together with GM-CSF is involved in inflammatory and autoimmune disease; Covid-19 patients have a significantly increased number of CCR6+ Th17 cells (4) ; elevated TH17 and IL-17 related pathways are increased in SARS-CoV, MERS-CoV, and H1N1 influenza virus patients (14-16); In MERS-CoV patients, IL-17 and low IFN $\gamma$ are associated with worse prognosis (14). Targeting beta-2adrenergic pathway was shown to reduce inflammatory cytokine and Th17 response in different settings such as cancer and autoimmune diseases. For this reason we believe that beta-2adrenergic pathway should be more deeply investigated as a possible target to reduce inflammation-related symptoms of SARS-CoV2.

\section{BETA-ADRENERGIC RECEPTORS AND IMMUNE SYSTEM}

$\beta$-Adrenergic receptors are G-protein coupled transmembrane proteins. There are three subtypes of $\beta$-adrenergic receptors $(\beta 1$ ARs, $\beta 2$-ARs, and $\beta 3$-ARs) that mediate a wide range of physiological responses to catecholamines epinephrine and norepinephrine, and thus play an important role in regulating cardiovascular responses in health and disease. $\beta$-Adrenoceptors regulate many aspects of airway function, including airway smooth muscle tone, mast cell mediator release, and plasma exudation. $\beta 1$-adrenergic receptors are located mainly in the heart and in the kidneys $(17,18) . \beta 2$-adrenergic receptors are located in the lungs, gastrointestinal tract, liver, uterus, vascular smooth muscle, and skeletal muscle $(17,18) . \beta 3$-adrenergic receptors are located in fat cells. More than $90 \%$ of all $\beta$ receptors in the human lung are located in the alveoli where the $\beta 2$-subtype predominates (70\%) (19). However, $\beta 1$ - and $\beta 2$ subtypes also coexist and are distributed uniformly in the alveolar walls. $\beta 2$-adrenergic receptors are expressed by all the cells of the immune system, including $\mathrm{T}$ and B lymphocytes, dendritic cells (DCs) and macrophages (20). The specific role of adrenergic signaling in regulating immune responses and inflammation is still under debate. However, there are many pieces of evidence supporting a proinflammatory action and promotion of TH17 response. Manni et al. showed that triggering $\beta 2$-adrenergic signal stimulates murine $\mathrm{DC}$ to secrete IL- 6 and promote a Th17 response (21). In DC, the $\beta 2$ adrenergic signal also reduces IL-12 and IFN $\gamma$ production but promotes IL-17. $\beta 2$-AR signaling plays a pivotal role in macrophage activation and proinflammatory cytokine production. Similarly, in other immune cells, the overall effect of $\beta 2$-adrenergic stimulation is an exacerbation of inflammation, promotion of B cell antibody production, and stimulation of DC and macrophages to secrete proinflammatory cytokines. Very interestingly, Chiarella et al. showed that $\beta 2$-AR on alveolar macrophages is responsible for IL-6 secretion and promotion of inflammation and prothrombotic state in a murine model of particulate-matter-induced thrombosis. Administration of $\beta 2$ $\mathrm{AR}$ agonist induces mitochondria-dependent reactive oxygen species (ROS) generation which results in cAMP response element-binding protein (CREB) that results in IL-6 activation. Huang et al. investigated the effect of lymphocyte-derived catecholamines on the differentiation and function of $\mathrm{T}$ helper (Th) cells, suggesting that this shifted the Th1/Th2 balance in the direction of greater Th2 polarization $(22,23)$. Panina-Bordignon et al. also showed that beta2-adrenergic signaling inhibits the production of IL-12, thereby promoting Th2 differentiation and inhibiting Th1 development associated with antitumor immunity. Catecholamines are also known to impact the immune response via down-regulation of IFN- $\gamma$ production 
(24). Functionally, IFN- $\gamma$ can exert direct antiviral effects on infected cells as well as neighboring cells $(25,26)$. It can also activate local immune cells, like tissue-resident dendritic cells, macrophages, and NK cells, to augment antiviral functions (24, $27-29)$. Furthermore, IFN- $\gamma$ can also control the antiviral state by modulating the differentiation and maturation of $\mathrm{T}$ cells and $\mathrm{B}$ cells $(30,31)$. Khalili et al. showed that propranolol, a nonselective beta-blocker, synergized with an HSP-70-rich tumor lysate vaccine to increase IFN- $\gamma$ production in a murine model of fibrosarcoma (32). Treated animals showed lower rates of tumor growth $(\mathrm{P}<0.01)$ and increased levels of CTL activity $(\mathrm{P}<0.05)$.

\section{BETA-BLOCKERS}

Beta-blockers are a class of medications that are prevalently used to manage abnormal heart rhythms, hypertension and to protect the heart from recurring myocardial infarction. There are two main categories of beta-blockers: non-selective and selective. The first group includes older molecules such as propranolol, nandol, timol, etc., which have different degrees of affinity for $\beta 2$ $\mathrm{AR}$ and $\beta 1-\mathrm{AR}$; second-generation drugs that are more selective such as metoprolol and acebutolol, etc. are specific for $\beta 1$ AR. After the introduction of cardioselective beta-blockers, the non-selective are not used frequently to treat heart conditions as the selective ones have fewer side effects. However, they are still in use to treat several other conditions such as long QT syndrome, aortic dilation in Marfan syndrome, liver cirrhosis to reduce portal hypertension and bleeding esophageal varices.

Propranolol, a non-selective beta-adrenergic blocker, has been extensively used for over 50 years in the treatment of many cardiovascular problems such as ischemic heart diseases, arrhythmias, and heart malfunction. Recently, several clinical trials are supporting its benefit in a number of conditions, including cancer, hemorrhage, sepsis, and hypermetabolic syndrome associated with severe burns, akathisia associated with Alzheimer's disease or psychosis, aggression associated with brain injury or disease, and anxiety (33-35). Two different reports on cancer patients show that propranolol treatment reduces inflammatory cytokines including IL-6 and $\mathrm{TNF} \alpha$, inflammation-related transcription factors such as NFKB and STAT3 and reduces the activation of Treg lymphocytes (36, 37). They also showed the potential benefit of propranolol on cancer recurrence (CR) and overall survival (OS) $(36,37)$. In these trials on breast cancer patients, propranolol treatment wellpreserved the anticancer immunological profiles of peripheral blood mononuclear cells, reduced EMT and prometastatic and proinflammatory transcription factors in tumor samples. In addition, Shaashua and colleagues (38) have suggested a positive synergistic effect of anti-inflammatory and betablockers, when these drugs are co-administered.

Beta-adrenergic receptor antagonists are also known to have effects on platelet aggregation, and a meta-analysis published in 2014 showed that they decreased platelet aggregation by $13 \%$ (95\% CI $=8-17 \%$, standardized mean difference $=-0.54,95 \%$ $\mathrm{CI}=-0.85$ to $-0.24, \mathrm{P}<0.0001$ ) (39). In particular non-selective lipophilic beta-blockers (including propranolol) decreased platelet aggregation more than that of the selective nonlipophilic beta-blockers. In addition, nonselective beta-blockers have been proved effective on the acute prothrombotic response to psychosocial stress and elevated plasma levels of factor VIII:C in patients with deep vein thrombosis $(40,41)$.

\section{OUR EXPERIENCE IN CANCER}

We had previously reported that propranolol reduces the effects of hypothalamic-pituitary-adrenal (HPA) axis stimulation induced by chronic stress. In particular, in a melanoma mouse model, propranolol treatment a week prior to the induction of stress delayed tumor growth. Furthermore, propranolol-treated mice showed lower levels of VEGF and eNOS with respect to untreated mice proving that it reduces the production of proangiogenic factors involved in tumor growth (42). Our reported findings also show that propranolol exerts antimetastatic effects on DU145 prostate cell lines xenograft in mice. It decreased metastatic foci in the inguinal lymph nodes, significantly reducing MMP2 and MMP9 in tumor samples. Moreover, a norepinephrine-dependent increase in epithelial to mesenchymal transition (EMT) can be rescued by propranolol treatment (43). Our preliminary data (Figure 1) in mouse lung colonization model of melanoma show a significative reduction of IL- 6 and IL-17A levels and an increase of IFN- $\gamma$ in mice treated with selective $\beta 2$-AR inhibitor ICI 118,551 (ICI). Moreover, our data show an increase of IL-12 as shown in ICItreated mice with respect to the controls.

\section{THE POSSIBLE BENEFIT OF B2-AR TARGETING IN PATIENTS WITH COVID-19}

The patients with SARS-CoV-2 at the late stages of the disease suffer from many abnormalities, which are the result of immune system imbalance and malfunction which can lead to proinflammatory reactions and immunopathological conditions, presented by lethal inflammation in the lungs and vascular leakage $(44,45)$. Several pieces of evidence support the pivotal role of IL- 6 in driving these phenomena. Indeed, clinical evidence from China and Italy in different hospitals (46) showed that the IL-R6 blocker Tocilizumab, normally used for the treatment of rheumatoid arthritis can effectively improve clinical conditions of patients. The $\beta 2$-AR blockade can reduce IL- 6 and other inflammatory cytokines in the patient's serum contributing to rebalancing the immune system. In 1980, Kaplan et al. suggested a possible role of propranolol in the treatment of rheumatoid arthritis (47). Moreover, the stress-induced inflammation, which likely occurs in patients diagnosed with Covid-19, could worsen the clinical symptoms; non-selective beta-blockers could prevent this phenomenon and at the same time reduce anxiety in those patients. Furthermore, the pericyte injury due to virus infection may result in capillary endothelial 


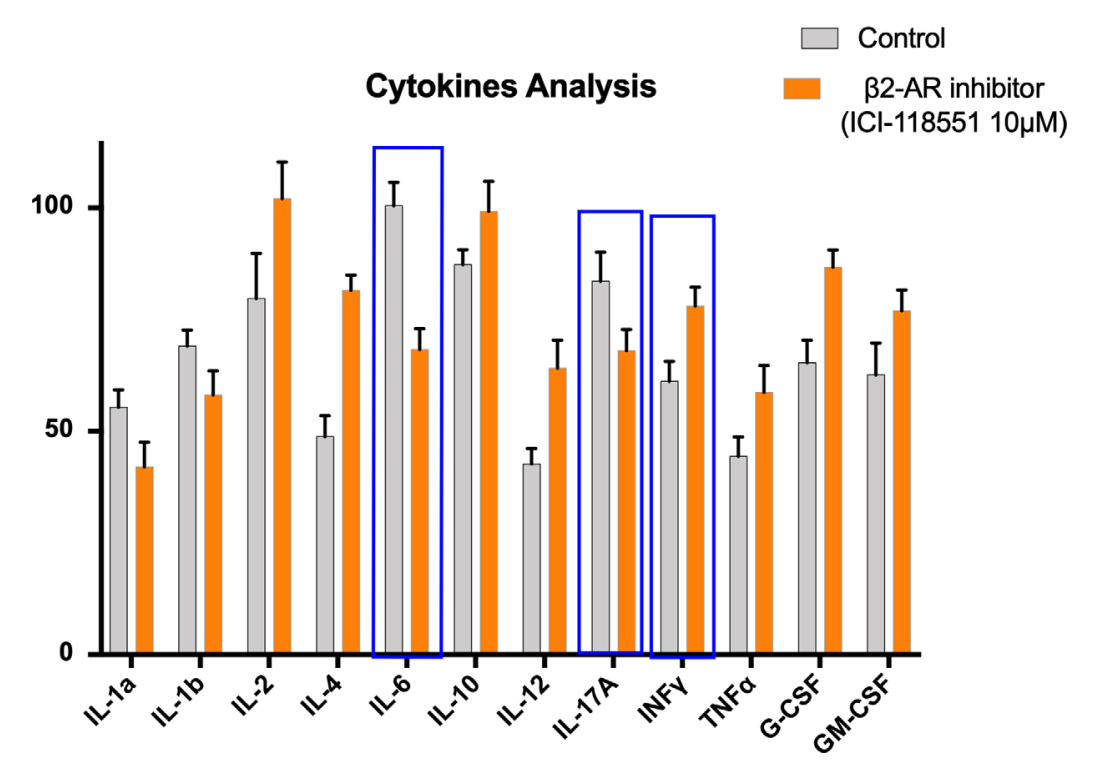

FIGURE 1 | Proinflammatory cytokines in mice untreated (Control) or treated with beta-2-inhibitor (ICl115,881). 12 Cytokine Multiplex assay was performed through the quantification in serum of IL-1 $\alpha$, IL-1 $\beta$, IL-2, IL-4, IL-6, IL-10, IL-12, IL17- $\alpha$, IFN- $\gamma$, TNF- $\alpha$, G-CSF, GM-CSF, in a lung colonization model of mice bearing murine melanoma cell line B16F10. Error bars depict means \pm SD. One-way ANOVA and Bonferroni post-hoc analysis were used to examine the significance of differences among groups (Graph pad Prism 8.0). A probability value with $\mathrm{P}<0.05$ was considered to be statistically significant.

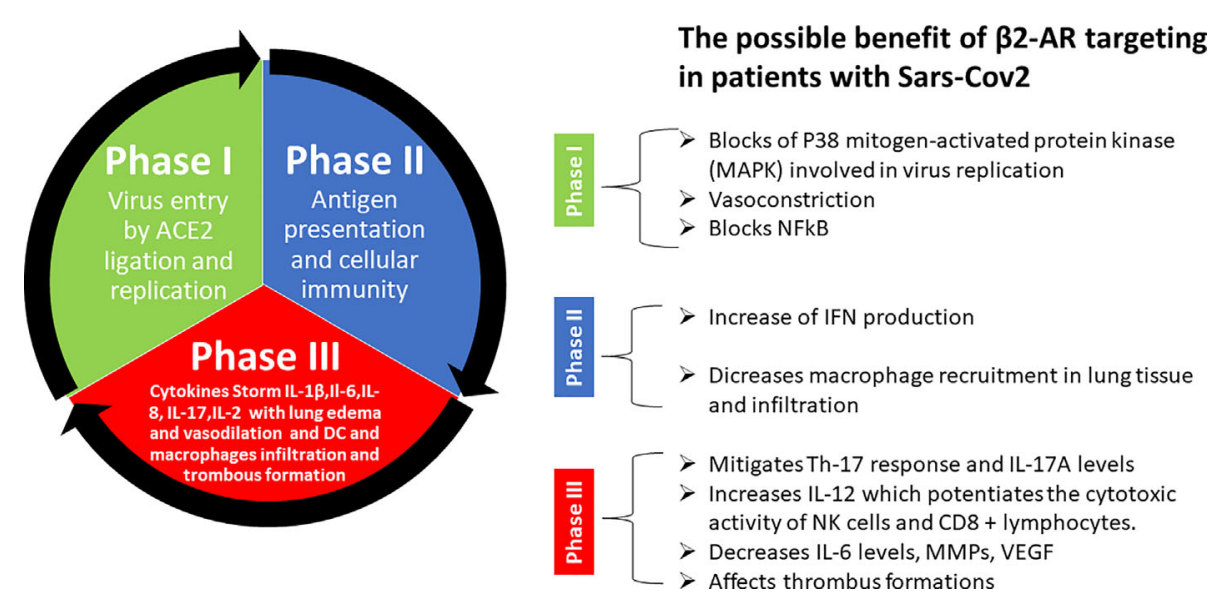

FIGURE 2 | Summary of possible benefits of $\beta 2$-AR targeting in patients with Sars-Cov-2. Explanation step by step of different phases of Sars-Cov-2 pathogenesis and possible tool offered by beta-blockers to prevent and counteract uncontrolled cytokine storm and thrombus formation in late phase III that lead to the death of patient.

cell dysfunction, inducing microvascular dysfunction (48). Indeed, Tang et al. proved that anticoagulant treatment is associated with decreased mortality in severe Covid-19 patients with coagulopathy (49). Beta-blocker might counteract this by reducing prothrombotic response, vascular tone, and VEGF secretion (50-52). Notably, some authors demonstrated that propranolol inhibits choroidal neovascularization $(\mathrm{CNV})$ in vivo and $\beta 2$-AR blockade reduces vascular endothelial growth factor (VEGF) expression in mouse retinal pigment epithelium and choroidal endothelial cells in culture (53).

\section{BETA-BLOCKERS AND RESPIRATORY DISEASES}

Since beta-blockers may cause bronchospasm, in some cases, their use is not recommended in Asthma or Chronic Obstructive Pulmonary Disease (COPD). However, a recent study on a large number of patients in Denmark showed that in patients taking beta-blockers (including non-selective) the risk of hospitalization for COPD is reduced (54). Similarly, in asthma, a recent systematic revision of the literature suggests that the escalating 
dose of beta-blockers is well tolerated and could be beneficial for airway inflammation and hyperresponsiveness (55). The patients positive for the SARS-CoV-2 did not describe any worsening of the symptoms. However, more accurate data are necessary to establish the safety of adrenergic targeting in these patients.

\section{CONCLUSIONS}

Many supporting pieces of evidence show that the major symptoms of Covid-19 infection are associated with hyperinflammation over-activation of Th17 response. Indeed, treatments known to reduce Th17 response such as Tocilizumab and Ruxolitinib have been already used to treat Covid-19 patients in phases II and III. $\beta 2$-AR signals have been described to have a central role in rheumatoid arthritis in promoting inflammation and Th17 response. Non-selective beta-blockers have been used in clinical settings to reduce inflammation and Th17 response. In addition, the non-selective beta-blocker propranolol blocks AT1 induced expression of IL-6, NFkB, TNF, IFN- $\gamma$, VEGF, and Metalloprotease Engagement. We believe that $\beta 2$-AR signals might be a valuable target for new strategies aiming to block or slow down the transition from the early phases (I and IIa) of Covid-19 to phase III by reducing the activation of Th17 response and inflammatory cytokine release and prevent venous thromboembolism (Figure 2). For these reasons we would like to point out the importance to perform further preclinical and clinical studies to explore this opportunity.

\section{REFERENCES}

1. Zumla A, Chan JFW, Azhar EI, Hui DSC, Yuen KY. Coronaviruses-drug discovery and therapeutic options. Nat Rev Drug Discovery (2016) 15:327-47. doi: $10.1038 /$ nrd.2015.37

2. Chan JFW, Lau SKP, Woo PCY. The emerging novel Middle East respiratory syndrome coronavirus: The "knowns" and "unknowns." J Formos Med Assoc (2013) 112:372-81. doi: 10.1016/j.jfma.2013.05.010

3. Cheng VCC, Lau SKP, Woo PCY, Kwok YY. Severe acute respiratory syndrome coronavirus as an agent of emerging and reemerging infection. Clin Microbiol Rev (2007) 20:660-94. doi: 10.1128/CMR.00023-07

4. Chan JFW, Lau SKP, To KKW, Cheng VCC, Woo PCY, Yue KY. Middle East Respiratory syndrome coronavirus: Another zoonotic betacoronavirus causing SARS-like disease. Clin Microbiol Rev (2015) 28:465-522. doi: 10.1128/CMR.00102-14

5. 武汉市卫生健康委员会. Available at: http://wjw.wuhan.gov.cn/front/web/ showDetail/2019123108989 (Accessed April 12, 2020).

6. Zhu N, Zhang D, Wang W, Li X, Yang B, Song J, et al. A novel coronavirus from patients with pneumonia in China, 2019. N Engl J Med (2020) 382:72733. doi: 10.1056/NEJMoa2001017

7. Gu J, Gong E, Zhang B, Zheng J, Gao Z, Zhong Y, et al. Multiple organ infection and the pathogenesis of SARS. J Exp Med (2005) 202:415-24. doi: $10.1084 /$ jem.20050828

8. Ding Y, He L, Zhang Q, Huang Z, Che X, Hou J, et al. Organ distribution of severe acute respiratory syndrome (SARS) associated coronavirus (SARS$\mathrm{CoV}$ ) in SARS patients: implications for pathogenesis and virus transmission pathways. J Pathol (2004) 203:622-30. doi: 10.1002/path.1560

9. Hamming I, Timens W, Bulthuis M, Lely A, Navis G, van Goor H. Tissue distribution of ACE2 protein, the functional receptor for SARS coronavirus. A first step in understanding SARS pathogenesis. J Pathol (2004) 203:631-7. doi: $10.1002 /$ path. 1570

\section{DATA AVAILABILITY STATEMENT}

The authors acknowledge that the data presented in this study must be deposited and made publicly available in an acceptable repository prior to publication. Frontiers cannot accept a manuscript that does not adhere to our open data policies.

\section{AUTHOR CONTRIBUTIONS}

$\mathrm{AB}$ and VD have thought and wrote the manuscript. NR critically revised the manuscript. GP revised immunological aspects and made corrections. NM made important contribution on beta-blockers. GB critically revised the manuscript and supervised the study. All authors contributed to the article and approved the submitted version.

\section{FUNDING}

This work was funded by an "Ricerca Corrente" grant from the Italian Ministry of Health.

\section{ACKNOWLEDGMENTS}

We thank Dr. Sandra Mazzoli for paper formatting, figure and test suggestions and Dr. Vincenzo Quagliariello for Elisa test on cytokines.

10. Diaz JH. Hypothesis: angiotensin-converting enzyme inhibitors and angiotensin receptor blockers may increase the risk of severe COVID-19. J Travel Med (2020) 27(3):taaa041. doi: 10.1093/jtm/taaa041

11. He F, Deng Y, Li W. Coronavirus Disease 2019 (COVID-19): What we know? J Med Virol (2020) 2019:0-2. doi: 10.1002/jmv.25766

12. Wang J, Jiang M, Chen X, Montaner LJ. Cytokine storm and leukocyte changes in mild versus severe SARS-CoV-2 infection: Review of 3939 COVID-19 patients in China and emerging pathogenesis and therapy concepts. J Leukoc Biol (2020) 108(1):17-41. doi: 10.1002/JLB.3COVR0520272R.

13. Wu D, Yang XO. TH17 responses in cytokine storm of COVID-19: An emerging target of JAK2 inhibitor Fedratinib. J Microbiol Immunol Infect (2020) 53(3):368-70. doi: 10.1016/j.jmii.2020.03.005

14. Faure E, Poissy J, Goffard A, Fournier C, Kipnis E, Titecat M, et al. Distinct immune response in two MERS-CoV-infected patients: Can we go from bench to bedside? PloS One (2014) 9:e88716. doi: 10.1371/journal.pone.0088716

15. Josset L, Menachery VD, Gralinski LE, Agnihothram S, Sova P, Carter VS, et al. Cell host response to infection with novel human coronavirus EMC predicts potential antivirals and important differences with SARS coronavirus. MBio (2013) 4(3):e001657-13. doi: 10.1128/mBio.00165-13

16. Li C, Yang P, Sun Y, Li T, Wang C, Wang Z, et al. IL-17 response mediates acute lung injury induced by the 2009 Pandemic Influenza A (H1N1) Virus. Cell Res (2012) 22:528-38. doi: 10.1038/cr.2011.165

17. Johnson M. Molecular mechanisms of $\beta 2$-adrenergic receptor function, response, and regulation. J Allergy Clin Immunol (2006) 117:18-24. doi: 10.1016/j.jaci.2005.11.012

18. Wachter SB, Gilbert EM. Beta-adrenergic receptors, from their discovery and characterization through their manipulation to beneficial clinical application. Cardiol (2012) 122:104-12. doi: 10.1159/000339271

19. Carstairs JR, Nimmo AJ, Barnes PJ. Autoradiographic visualization of betaadrenoceptor subtypes in human lung. Am Rev Respir Dis (1985) 132:541-7. doi: 10.1164/arrd.1985.132.3.541 
20. Wu L, Tai Y, Hu S, Zhang M, Wang R, Zhou W, et al. Bidirectional role of $\beta 2$ adrenergic receptor in autoimmune diseases. Front Pharmacol (2018) 9:1313. doi: 10.3389/fphar.2018.01313

21. Manni M, Granstein RD, Maestroni G. $\beta 2$-Adrenergic agonists bias TLR-2 and NOD2 activated dendritic cells towards inducing an IL-17 immune response. Cytokine (2011) 55:380-6. doi: 10.1016/j.cyto.2011.05.013

22. Huang H-W, Fang X-X, Wang X-Q, Peng Y-P, Qiu Y-H. Regulation of Differentiation and Function of Helper T Cells by Lymphocyte-Derived Catecholamines via $\alpha_{1}$ - and $\beta_{2}$-Adrenoceptors. Neuroimmunomodulation (2015) 22:138-51. doi: 10.1159/000360579

23. Huang HW, Tang JL, Han XH, Peng YP, Qiu YH. Lymphocyte-derived catecholamines induce a shift of Th1/Th2 balance toward Th2 polarization. Neuroimmunomodulation (2012) 20:1-8. doi: 10.1159/000343099

24. Sonnenfeld G, Cunnick JE, Armfield AV, Wood PG, Rabin BS. Stress-induced alterations in interferon production and class II histocompatibility antigen expression. Brain Behav Immun (1992) 6:170-8. doi: 10.1016/0889-1591(92) 90016- $\mathrm{H}$

25. Hwang S, Maloney NS, Bruinsma MW, Goel G, Duan E, Zhang L, et al. Nondegradative role of Atg5-Atg12/Atg16L1 autophagy protein complex in antiviral activity of interferon gamma. Cell Host Microbe (2012) 11:397-409. doi: 10.1016/j.chom.2012.03.002

26. Changotra H, Jia Y, Moore TN, Liu G, Kahan SM, Sosnovtsev SV, et al. Type I and Type II Interferons Inhibit the Translation of Murine Norovirus Proteins. J Virol (2009) 83:5683-92. doi: 10.1128/jvi.00231-09

27. Nathan CF, Murray HW, Wlebe IE, Rubin BY. Identification of interferon- $\gamma$, as the lymphokine that activates human macrophage oxidative metabolism and antimicrobial activity. J Exp Med (1983) 158:670-89. doi: 10.1084/jem.158.3.670

28. Senik A, Stefanos S, Kolb JP, Lucero M, Falcoff E. Enhancement of mouse natural killer cell activity by type II interferon. Ann Immunol (Paris) 131C:349-61.

29. Sidman CL, Marshall JD, Shultz LD, Gray PW, Johnson HM. Gammainterferon is one of several direct B cell-maturing lymphokines. Nature (1984) 309:801-4. doi: 10.1038/309801a0

30. Lee C-K, Rao DT, Gertner R, Gimeno R, Frey AB, Levy DE. Distinct Requirements for IFNs and STAT1 in NK Cell Function. J Immunol (2000) 165:3571-7. doi: 10.4049/jimmunol.165.7.3571

31. Weizman O-E, Adams NM, Schuster IS, Krishna C, Pritykin Y, Lau C, et al. ILC1 Confer Early Host Protection at Initial Sites of Viral Infection. Cell (2017) 171:795-808.e12. doi: 10.1016/j.cell.2017.09.052

32. Khalili A, Hassan ZM, Shahabi S, Pourfathollah AA, Ostad SN, Noori S, et al. Long acting propranolol and HSP-70 rich tumor lysate reduce tumor growth and enhance immune response against fibrosarcoma in Balb/c mice. Iran J Immunol (2013) 10(2):70-82.

33. Ali A, Herndon DN, Mamachen A, Hasan S, Andersen CR, Grogans R-J, et al. Propranolol attenuates hemorrhage and accelerates wound healing in severely burned adults. Crit Care (2015) 19:217. doi: 10.1186/s13054-015-0913-x

34. Peskind ER, Tsuang DW, Bonner LT, Pascualy M, Riekse RG, Snowden MB, et al. Propranolol for disruptive behaviors in nursing home residents with probable or possible Alzheimer disease: A placebo-controlled study. Alzheimer Dis Assoc Disord (2005) 19:23-8. doi: 10.1097/01.wad.0000155067.16313.5e

35. Greendyke RM, Kanter DR, Schuster DB, Verstreate S, Wootton J. Propranolol treatment of assaultive patients with organic brain disease: A double-blind crossover, placebo-controlled study. J Nerv Ment Dis (1986) 174:290-4. doi: 10.1097/00005053-198605000-00005

36. Haldar R, Shaashua L, Lavon H, Lyons YA, Zmora O, Sharon E, et al. Perioperative inhibition of $\beta$-adrenergic and COX2 signaling in a clinical trial in breast cancer patients improves tumor Ki-67 expression, serum cytokine levels, and PBMCs transcriptome. Brain Behav Immun (2018) 73:294-309. doi: 10.1016/j.bbi.2018.05.014

37. Zhou L, Li Y, Li X, Chen G, Liang H, Wu Y, et al. Propranolol Attenuates Surgical Stress-Induced Elevation of the Regulatory T Cell Response in Patients Undergoing Radical Mastectomy. J Immunol (2016) 196:3460-9. doi: 10.4049/jimmunol.1501677

38. Shaashua L, Shabat-Simon M, Haldar R, Matzner P, Zmora O, Shabtai M, et al. Perioperative COX-2 and $\beta$-Adrenergic Blockade Improves Metastatic Biomarkers in Breast Cancer Patients in a Phase-II Randomized Trial. Clin Cancer Res (2017) 23:4651-61. doi: 10.1158/1078-0432.CCR-17-0152

39. Bonten TN, Plaizier CEI D, Snoep JJ, Stijnen T, Dekkers OM, Van Der Bom JG. Effect of $\beta$-blockers on platelet aggregation: A systematic review and meta-analysis. Br J Clin Pharmacol (2014) 78:940-9. doi: 10.1111/bcp. 12404

40. von Känel R, Kudielka BM, Helfricht S, Metzenthin P, Preckel D, Haeberli A, et al. The effects of aspirin and nonselective beta blockade on the acute prothrombotic response to psychosocial stress in apparently healthy subjects. J Cardiovasc Pharmacol (2008) 51:231-8. doi: 10.1097/FJC.0b013e318161ea63

41. Hoppener MR, Kraaijenhagen RA, Hutten BA, Büller HR, Peters RJG, Levi M. Beta-receptor blockade decreases elevated plasma levels of factor VIII: C in patients with deep vein thrombosis. J Thromb Haemost (2004) 2:1316-20. doi: 10.1111/j.1538-7836.2004.00851.x

42. Barbieri A, Palma G, Rosati A, Giudice A, Falco A, Petrillo A, et al. Role of endothelial nitric oxide synthase (eNOS) in chronic stress-promoted tumour growth. J Cell Mol Med (2012) 16:920-6. doi: 10.1111/j.1582-4934.2011.01375.x

43. Barbieri A, Bimonte S, Palma G, Luciano A, Rea D, Giudice A, et al. The stress hormone norepinephrine increases migration of prostate cancer cells in vitro and in vivo. Int J Oncol (2015) 47:527-34. doi: 10.3892/ijo.2015.3038

44. Shahabi nezhad F, Mosaddeghi P, Negahdaripour M, Dehghani Z, Farahmandnejad M, Moghadami M, et al. Therapeutic Approaches for COVID-19 Based on the Dynamics of Interferon-mediated Immune Responses. Preprints (2020) 2020030206. doi: 10.20944/preprints202003.0206.v1

45. Channappanavar R, Fehr AR, Vijay R, Mack M, Zhao J, Meyerholz DK, et al. Dysregulated Type I Interferon and Inflammatory Monocyte-Macrophage Responses Cause Lethal Pneumonia in SARS-CoV-Infected Mice. Cell Host Microbe (2016) 19:181-93. doi: 10.1016/j.chom.2016.01.007

46. Buonaguro FM, Puzanov I, Ascierto PA. Anti-IL6R role in treatment of COVID-19related ARDS. J Transl Med (2020) 18(1):165. doi: 10.1186/s12967-020-02333-9

47. Kaplan R, Robinson CA, Scavulli JF, Vaugha JH. Propranolol and the treatment of rheumatoid arthritis. Arthritis Rheum (1980) 23:253-5. doi: 10.1002/art.1780230220

48. Chen L, Li X, Chen M, Feng Y, Xiong C. The ACE2 expression in human heart indicates new potential mechanism of heart injury among patients infected with SARS-CoV-2. Cardiovasc Res (2020) 116(6):1097-100. doi: 10.1093/cvr/cvaa078

49. Tang N, Bai H, Chen X, Gong J, Li D, Sun Z. Anticoagulant treatment is associated with decreased mortality in severe coronavirus disease 2019 patients with coagulopathy. J Thromb Haemost (2020) 18(5):1094-9. doi: 10.1111/jth.14817

50. Madden KS, Szpunar MJ, Brown EB. $\beta$-Adrenergic receptors ( $\beta$-AR) regulate VEGF and IL-6 production by divergent pathways in high $\beta$-AR-expressing breast cancer cell lines. Breast Cancer Res Treat (2011) 130:747-58. doi: 10.1007/ s10549-011-1348-y

51. Stohl LL, Zang JB, Ding W, Manni M, Zhou XK, Granstein RD. Norepinephrine and adenosine-5'-triphosphate synergize in inducing IL-6 production by human dermal microvascular endothelial cells. Cytokine (2013) 64:605-12. doi: 10.1016/j.cyto.2013.08.005

52. Yang EV, Kim Sj, Donovan EL, Chen M, Gross AC, Webster Marketon JI, et al. Norepinephrine upregulates VEGF, IL-8, and IL-6 expression in human melanoma tumor cell lines: Implications for stress-related enhancement of tumor progression. Brain Behav Immun (2009) 23:267-75. doi: 10.1016/j.bbi.2008.10.005

53. Lavine JA, Farnoodian M, Wang S, Darjatmoko SR, Wright LS, Gamm DM, et al. $\beta 2$-adrenergic receptor antagonism attenuates $\mathrm{CNV}$ through inhibition of VEGF and IL-6 expression. Invest Ophthalmol Vis Sci (2017) 58:299-308. doi: $10.1167 /$ iovs.16-20204

54. Nielsen AO, Pedersen L, Sode BF, Dahl M. ß-Blocker Therapy and Risk of Chronic Obstructive Pulmonary Disease - A Danish Nationwide Study of 1.3 Million Individuals. EClinicalMedicine (2019) 7:21-6. doi: 10.1016/j.eclinm.2019.01.004

55. Arboe B, Ulrik CS. Beta-blockers: Friend or foe in asthma? Int J Gen Med (2013) 6:549-55. doi: 10.2147/IJGM.S46592

Conflict of Interest: The authors declare that the research was conducted in the absence of any commercial or financial relationships that could be construed as a potential conflict of interest.

Copyright (c) 2020 Barbieri, Robinson, Palma, Maurea, Desiderio and Botti. This is an open-access article distributed under the terms of the Creative Commons Attribution License (CC BY). The use, distribution or reproduction in other forums is permitted, provided the original author(s) and the copyright owner(s) are credited and that the original publication in this journal is cited, in accordance with accepted academic practice. No use, distribution or reproduction is permitted which does not comply with these terms. 